\title{
Thalidomide inhibits the gene promoter of connective tissue growth factor in human embryonic lung fibroblasts
}

\author{
Yonghui $\mathrm{Wu}^{1 \#}$, Libao Liu ${ }^{1 \#}$, Jian Zhang ${ }^{1}$, Lei Huang ${ }^{1}$, Shaohong Huang ${ }^{1}$, Jinyuan $\mathrm{He}^{2}$ \\ ${ }^{1}$ Department of Cardiothoracic Surgery, ${ }^{2}$ Department of Gastroenterology, The Third Affiliated Hospital of Sun Yat-sen University, Guangzhou, China \\ Contributions: (I) Conception and design: Y Wu, L Liu, J He; (II) Administrative support: J Zhang, L Huang; (III) Provision of study materials or \\ patients: Y Wu, S Huang ; (IV) Collection and assembly of data: L Liu, J Zhang; (V) Data analysis and interpretation: Y Wu, L Liu, J He; (VI) \\ Manuscript writing: All authors; (VII) Final approval of manuscript: All authors. \\ \#These authors contributed equally to this work. \\ Correspondence to: Jinyuan He. No. 600 Tianhe Road, Tianhe District, Guangzhou, China. Email: caryxiang1007@163.com.
}

\begin{abstract}
Background: The etiology and pathogenesis of idiopathic pulmonary fibrosis (IPF) remain unclear, and the early detection and treatment are vital to the prognosis of IPF patients. It's necessary to investigate the effect of thalidomide on the gene promoter activation of connective tissue growth factor (CTGF) induced by transforming growth factor- $\beta 1$ (TGF- $\beta 1$ ) in human embryonic lung fibroblast (HELF).

Methods: The gene vector of pGL3-CTGFP containing human CTGF gene promoter was constructed and transfected into HELF cells. We used different TGF- $\beta 1(0,2.5,5,10$ and $20 \mu \mathrm{g} / \mathrm{L}$ respectively) to stimulate HELF to identify the optimal concentration for gene promoter of CTGF. The activity of luciferase was measured to observe the effect of TGF- $\beta 1$ and THALIDOMIDE on the activity of CTGF gene promoter.

Results: The relative luciferase activity increased significantly with the stimulation of TGF- $\beta 1$, and the relative luciferase activity peaked in the $5 \mu \mathrm{g} / \mathrm{L}$ TGF- $\beta 1$ group (all $\mathrm{P}<0.01$ ). The thalidomide inhibited the TGF- $\beta 1$-induced activation of CTGF gene promoter in HELF, and the effect peaked in the $25 \mu \mathrm{g} / \mathrm{L}$ group (all $\mathrm{P}<0.001)$.

Conclusions: Thalidomide produces a significant inhibitory effect on the gene promoter activation of CTGF induced by TGF- $\beta 1$ in HELF, it may be a potentially effective drug for the treatment of pulmonary fibrosis.
\end{abstract}

Keywords: Thalidomide; transforming growth factor- $\beta 1$ (TGF- $\beta 1$ ); connective tissue growth factor (CTGF); human embryonic lung fibroblasts (HELF)

Submitted Oct 20, 2019. Accepted for publication Apr 07, 2020.

doi: 10.21037/apm-19-398

View this article at: http://dx.doi.org/10.21037/apm-19-398

\section{Introduction}

Idiopathic pulmonary fibrosis (IPF) is a common type of lung disorders with an incidence of 8.6-31.6/100,000 around the world $(1,2)$. Currently, the causes of IPF remain unclear, and the prognosis is extremely poor (3). The pathogenesis of interstitial lung disease is complex, the progress of interstitial lung disease is irreversible, early diagnosis is difficult yet vital to the clinical medicine treatment. Therefore, at present, the pathogenesis of interstitial lung disease has become a hot topic at home and abroad.

At present, the etiology and pathogenesis of IPF are still unclear. From the chronic inflammatory hypothesis proposed in the 1980 s to the abnormal repair after epithelial cell injury proposed in the early 21 st century, the pathogenesis of IPF remains controversial and there is no conclusion (4). It's well-known that the pathogenesis of IPF involves many cells, cytokines, chemokines, and gene phenotypes. After unexplained lung injury, various 


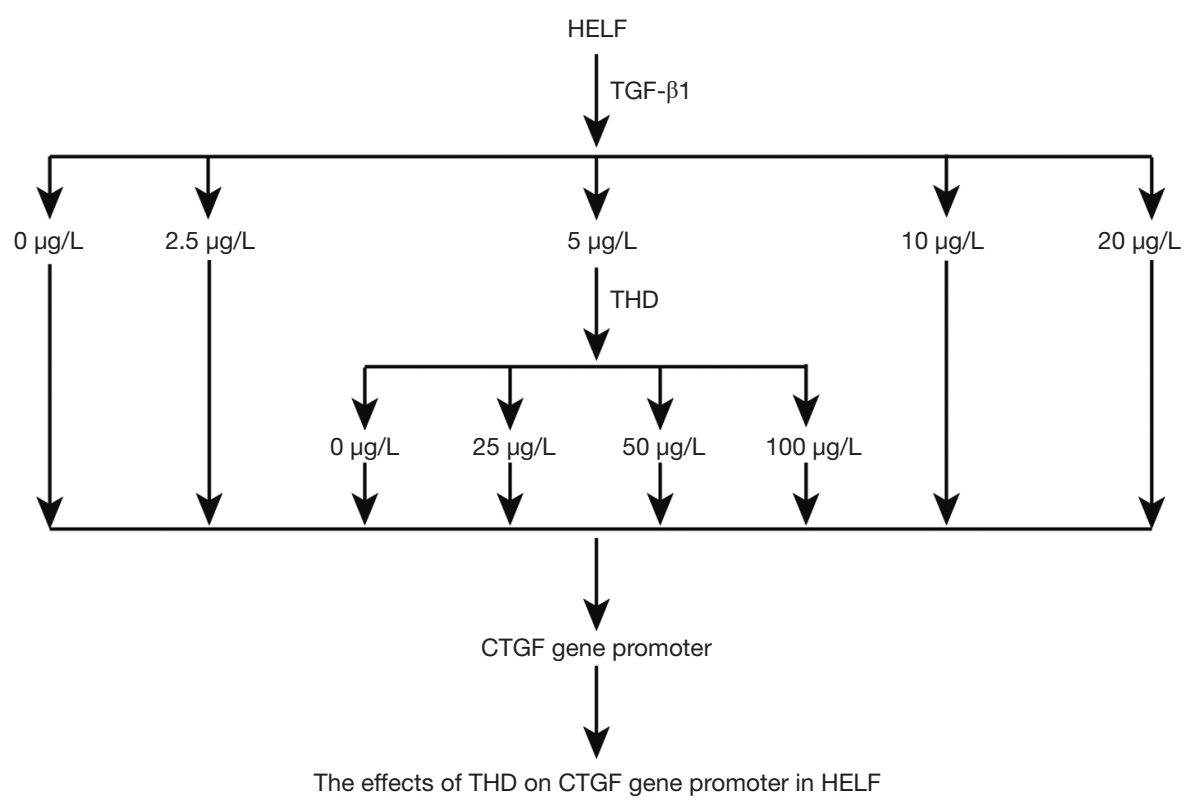

Figure 1 The flow chart of study design. CTGF, connective tissue growth factor; HELF, human embryonic lung fibroblast; TGF- $\beta 1$, transforming growth factor- $\beta 1$.

cells and cytokines interact with each other to eventually form pulmonary interstitial fibrosis $(5,6)$. It can be seen that various cells and cytokines play an important role in the pathogenesis of IPF. Transforming growth factor $\beta 1$ (TGF- $\beta 1$ ) induces increased expression of connective tissue growth factor (CTGF) in various cells such as lung fibroblasts, which is considered to be an important process in the pathogenesis of pulmonary fibrosis $(7,8)$. Therefore, it's highlighted that more studies on the role of CTGF in IPF should be conducted to elucidate the mechanism of IPF.

Thalidomide is currently used for the treatment of diseases such as leprosy and multiple myeloma $(9,10)$. Several studies (11-13) have found that thalidomide may also has good anti-pulmonary fibrosis effects, but the underlying pharmacological mechanisms have not been well-elucidated. Therefore, more studies on this issue are warranted. In this study, we aimed to analyze the effect of thalidomide on the activation of CTGF gene promoter induced by TGF- $\beta 1$ in human embryonic lung fibroblast (HELF), thereby providing further evidence on the treatment of IPF.

\section{Methods}

\section{Ethics approval}

This present study obtained ethics approval from the ethics committee of our hospital (2018-1029-c1) and was conducted in accordance with the Declaration of Helsinki (as revised in 2013).

\section{Study design}

This present study was generally divided into two parts (Figure 1): Part one focused on the effects of TGF- $\beta 1$ on CTGF gene promoter in HELF, and part two focused on the role of THALIDOMIDE with different concentration on the CTGF gene promoter in HELF. As Figure 1 presented, we used different TGF- $\beta 1(0,2.5,5,10$ and $20 \mu \mathrm{g} / \mathrm{L}$ respectively) to stimulate HELF to identify the optimal concentration for gene promoter of CTGF, thus providing basis for the conducts of Part two. In parts two, we investigated the pharmacological effects of THALIDOMIDE with different concentration $(0,25,50$ and $10 \mu \mathrm{g} / \mathrm{L}$ respectively) on gene promoter of CTGF. With this two parts combined, we attempted to identify the role of THALIDOMIDE on gene promoter of CTGF in HELF.

\section{Materials}

DMEM cell culture solution (Combo, German); calf serum (S100, Mingqi, China); CTM DNA ladder, XIG MasterMix kit and competent E. coli DH5a (Fiksy, 
Guangzhou, China); Endonuclease HindIII and BglII (Toyobo); W4 DNA ligase (WKE, Nanjing, China); pGL3-Basic plasmid, pRL-SV40 plasmid and luciferase assay kit Dual-Luciferase Reporter Assay System (Crisky, Japan); PCR product extraction Kit and Detulin Plasmid Kit (Biosida, German), GeneFinderTM Nucleic Acid Dye (Fangzheng, Xiamen, China); Agarose (Nexy, Wuahan, China); Liposomal Polyplus-transfection Kit (Brant, USA); Human Recombinant TGF- $\beta 1$ (Xiyuan, Shanghai, China); THALIDOMIDE (Sigma, USA).

\section{The culture of HELF}

The HELF cells were provided by the Cell Center of Chinese Academy of Medical Sciences. The obtained HELF cells were inoculated into a $150 \mathrm{~mm}$ culture dish containing $10 \%$ calf serum and DMEM medium. and the cells were cultured in $5 \% \mathrm{CO}_{2}, 37{ }^{\circ} \mathrm{C}$ until the degree of cell fusion is about $70 \%$, then we used DMEM medium containing no calf serum to culture for $24 \mathrm{~h}$, and then further drug treatment were made.

\section{Drug treatment}

When the HELFs were prepared, the recombinant plasmid pGL3-CTGFP was transfected into the cultured HELF cells with liposome, and the pRL-SV40 plasmid containing Renilla luciferase was transfected as an internal reference. After $24 \mathrm{~h}$ of culture, TGF- $\beta 1$ with concentration of $0,2.5$, 5,10 and $20 \mu \mathrm{g} / \mathrm{L}$ was added respectively in the experiments of Part one. Or with $5 \mu \mathrm{g} / \mathrm{L}$ TGF- $\beta 1$ adding, further THALIDOMIDEs with concentrations of $0,25,50$ and $100 \mu \mathrm{g} / \mathrm{L}$ were added in the experiments of part two.

\section{Construction of luciferase reporter gene recombinant plasmid pGL3-CTGFP}

According to human CTGF gene promoter sequence (GenBank, AF316368), primers were synthesized by professional gene-editing company (Hengsheng, Shanghai), the upstream primers were 5'-GCCAGATCTTCCCT TTTTCTGGAAACATTGATGG-3' ( $B g l \mathrm{II}$ ), and the downstream primers were 5'-CTGAAGCTTCTGACAGG GCGAGGAGGAGGAC-3' (Hind III). The human CTGF gene promoter fragment was obtained by PCR amplification using normal human peripheral blood leukocyte cDNA was selected as template. The length of the PCR product was
$1,026 \mathrm{bp}$. The reaction conditions were: pre-denaturation at $94{ }^{\circ} \mathrm{C}$ for $2 \mathrm{~min}, 94^{\circ} \mathrm{C}$ for $30 \mathrm{~s}, 60^{\circ} \mathrm{C}$ for $30 \mathrm{~s}, 68^{\circ} \mathrm{C} 1 \mathrm{~min}$, a total of 35 cycles. The vector pGL3-Basic was digested with restriction endonucleases BgIII and HindIII, and the PCR target fragment was ligated into the restriction vector with T4 ligase to construct the pGL3-CTGFP recombinant plasmid. The recombinant plasmid was then sent to senior gene company (Hua Da Gene, China) for verification.

\section{Detection on the expression of CTGF gene promoter}

The HELF cells were cultured and transfected accordingly. In accordance to the Operating Manual of Dual-Luciferase Reporter Assay System Kit (Hengsheng, Shanghai), using the MD-SpectraMax C5 (Olympia X90, Japan) to detect the luminescence of two luciferases at 560 and $465 \mathrm{~nm}$, with firefly luciferase luminescence values, and the ratio of firefly luciferase luminescence/renal luciferase luminescence (F/R) was defined as relative luciferase activity to reflect the activity of the CTGF gene promoter, the examination was repeated 3 times for each group.

\section{Hematoxylin and eosin (HE) staining}

We used HE staining to detect how cells survive. HE staining was conducted as previously described (14). The specimens were examined and photographed by a light microscope (Olympus OX 90) at 40x and 100× field of view.

\section{Statistical analysis}

Data were analyzed using SPSS 11.0 statistical software. The continuous variables are presented as mean and standard deviation. Comparisons between groups were performed by one-way analysis of variance (ANOVA), and the Bonferroni method was used for inter-group comparison. $\mathrm{P}<0.05$ was considered that the difference was statistically significant.

\section{Results}

\section{The culture of HELF}

The morphology of fibroblasts was observed under inverted micro-scope. It was indicated that the HELF was successfully cultured (Figure 2A,B), and further verified by HE staining (Figure 2C,D). 

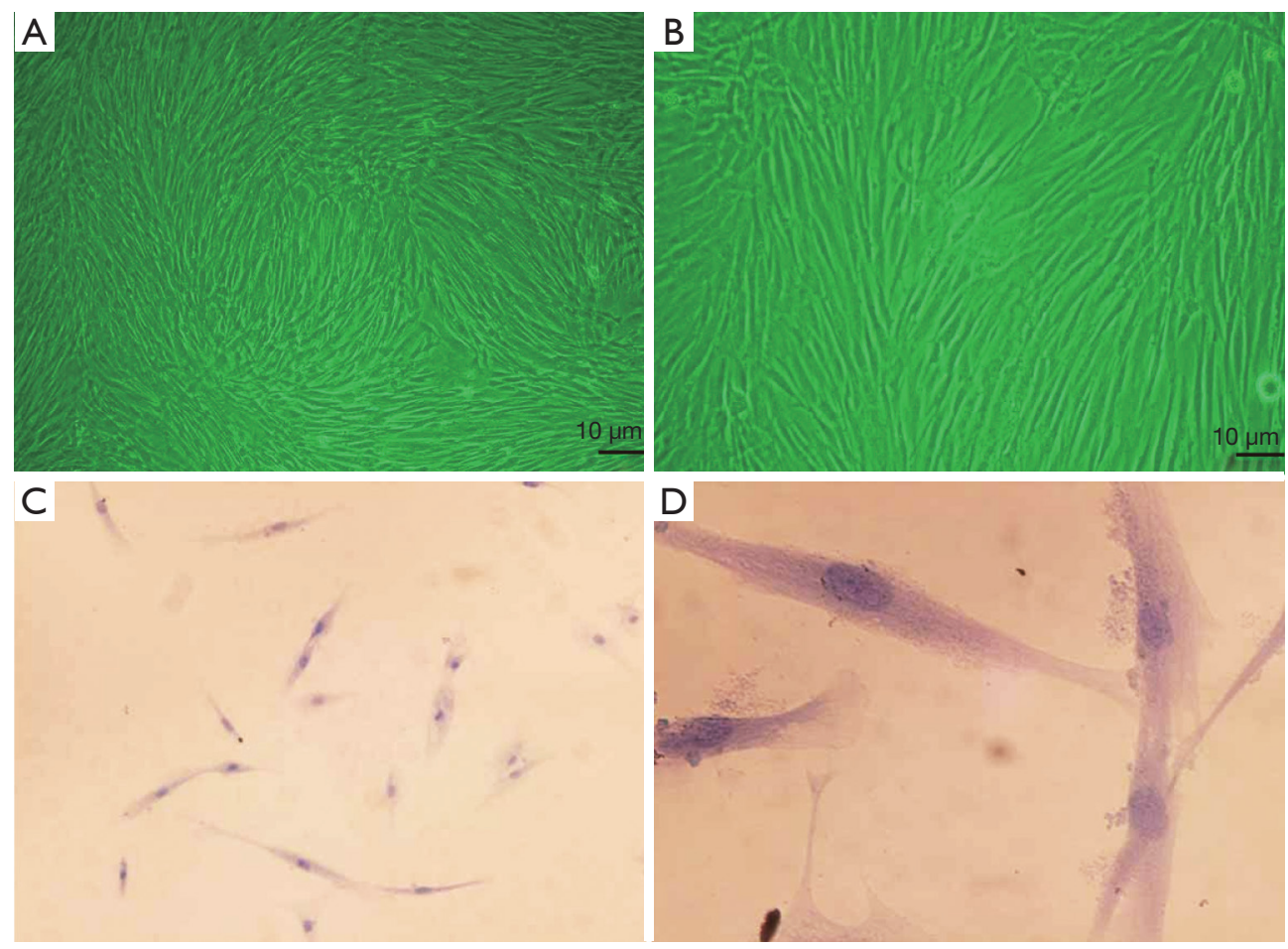

Figure 2 The verification of human embryonic lung fibroblast (HELF) culture. (A,B) Morphology of fibroblasts observed under inverted micro-scope $(\mathrm{A} \times 40, \mathrm{~B} \times 100)$; $(\mathrm{C}, \mathrm{D}) \mathrm{HE}$ staining of $\mathrm{HELF}(\mathrm{C} \times 40, \mathrm{D} \times 100)$.

\section{Identification of recombinant plasmid pGL3-CTGFP}

The PCR amplification product of CTGFP-biotin probe showed a clear band at 1,000 bp (1,026 bp) after electrophoresis on $1 \%$ agarose gel, which was consistent with the expected size of the amplified fragment, indicating that CTGFP-biotin probe was successfully amplified, as shown in Figure 3.

\section{Effect of TGF- $\beta 1$ on CTGF gene promoter activity in HELF cells}

As Figure 4 showed, the relative luciferase activity increased significantly with the stimulation of TGF- $\beta 1$, and the relative luciferase activity peaked in the $5 \mu \mathrm{g} / \mathrm{L}$ group. Therefore, we chose the $5 \mu \mathrm{g} / \mathrm{L}$ group for further thalidomide intervention.

\section{Thalidomide inbibited the TGF- $\beta 1$-induced activation of CTGF gene promoter}

As Figure 5 showed, the thalidomide produced a significantly inhibited effect on the TGF- $\beta 1$-induced activation of CTGF gene promoter in HELF, and the effect peaked in the $25 \mu \mathrm{g} / \mathrm{L}$ group.

\section{Discussion}

CTGF is a cysteine-rich, secreted polypeptide, which is widely found in many tissues and organs such as human heart, lung, liver, kidney etc. $(15,16)$. It's been reported that CTGF is mitogenic, it can stimulate the cell migration, cell adhesion, and it promotes the cell phenotypic transformation and fibroblast proliferation, by which promoting the biological process of angiogenesis (17-19). The over-expressed CTGF is closely related to the pathogenesis of organ fibrosis such as pulmonary fibrosis, cirrhosis, and diabetic nephropathy (20,21). Previous study has found that CTGF mRNA and protein expression are up-regulated in the alveolar lavage fluid and fibrotic lung tissue in patients with IPF (22). Meanwhile, in situ hybridization and immunohistochemistry have observed upregulation of CTGF mRNA and protein expression in lung tissue of patients with IPF, and it's positively correlated with the expression level of fibronectin (23). CTGF is involved in the transformation of lung fibroblasts into myofibroblasts, 


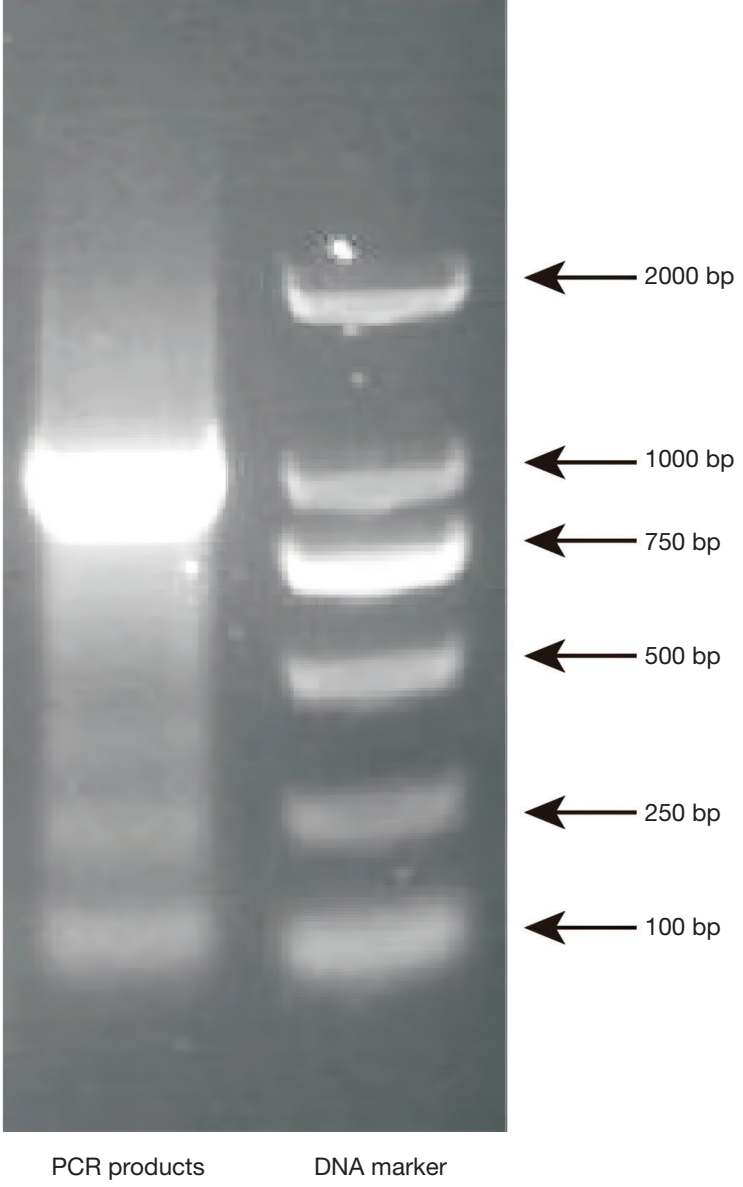

Figure $3 \mathrm{Gel}$ electrophoresis of connective tissue growth factorbiotin probe amplified by PCR.

and myofibroblasts are the main source of collagen fibers in the IPF $(24,25)$. Furthermore, it's been reported that CTGF-siRNA can inhibit the proliferation, phenotypic transformation and extracellular matrix synthesis of lung fibroblasts (26).

It's been found that TGF- $\beta 1$ is one of the most important fibrotic factors in organ fibrosis and is overexpressed in liver, lung, kidney and other organ fibrosis models $(27,28)$. Previous studies have shown that CTGF is an important downstream factor mediating TGF- $\beta 1$ profibrosis (29-31). In vitro cell culture experiments have showed that lung fibroblasts can not only express CTGF, but also induce a significant increase in CTGF expression when TGF- $\beta 1$ is added to the culture medium. There is a TGF- $\beta$ response element at the CTGF promoter-157 to -145 , and the mutations in this region can abolish the induction of TGF- $\beta 1$ to CTGF (29). Therefore, the antisense CTGF technology

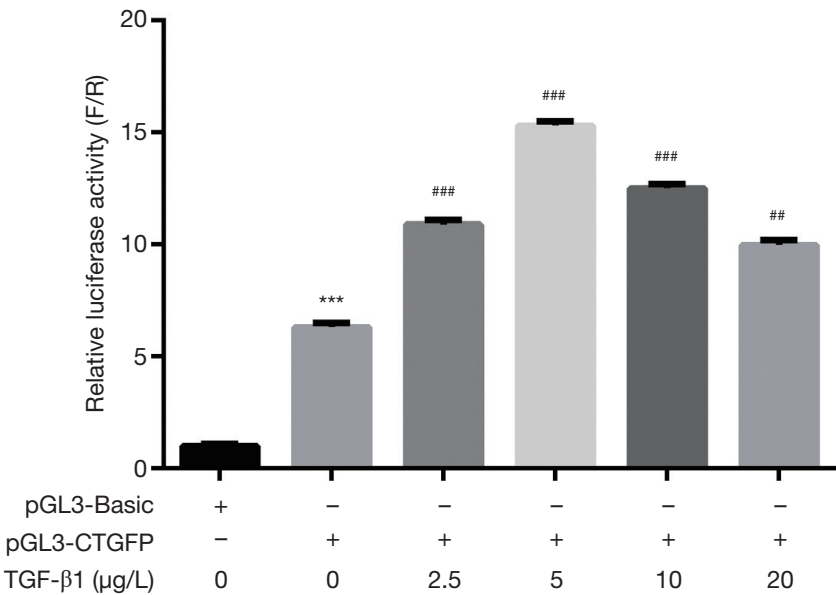

Figure 4 The dose-effect relationship of connective tissue growth factor gene promoter activation by TGF- $\beta 1$ in human embryonic lung fibroblast. ${ }^{* * *}, \mathrm{P}<0.001$ vs. blank group (with pGL3-Basic alone); ${ }^{\# \#, ~} \mathrm{P}<0.001$ vs. control group (with pGL3-CTGFP alone); \#, $\mathrm{P}<0.01$ vs. control group (with pGL3-CTGFP alone). TGF- $\beta 1$, transforming growth factor- $\beta 1$.

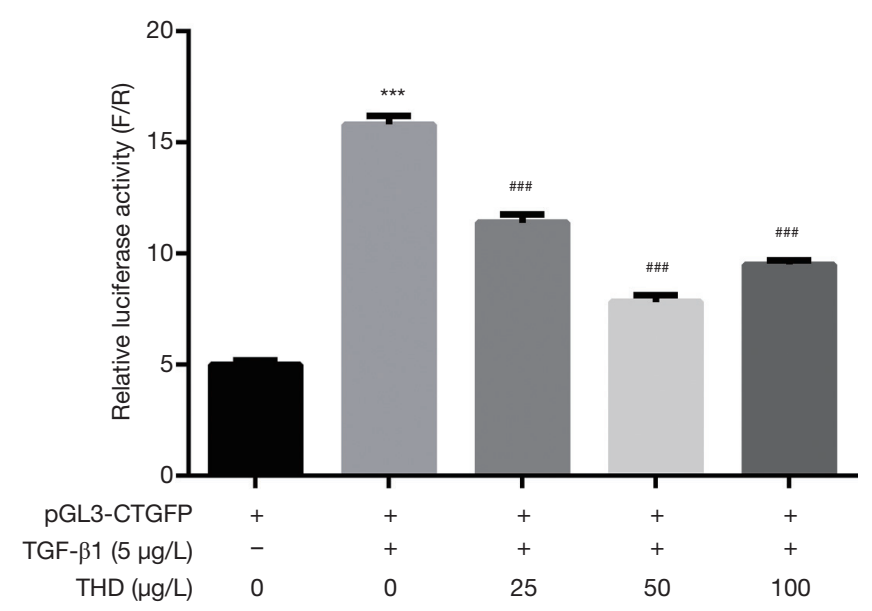

Figure 5 Effects of thalidomide on TGF- $\beta 1$-induced activation of connective tissue growth factor gene promoter in human embryonic lung fibroblast. ${ }^{* * *}, \mathrm{P}<0.001$ vs. non-TGF- $\beta 1$ group; ${ }^{\# \# \#, ~}$ $\mathrm{P}<0.001$ vs. control group (with pGL3-CTGFP and TGF- $\beta 1$ yet without thalidomide). TGF- $\beta 1$, transforming growth factor- $\beta 1$.

can potentially block the profibrotic effects caused by TGF- $\beta 1$ (32). However, the TGF- $\beta 1$ plays a doublesided act, which not only plays a positive role in inhibiting inflammation and excessive cell proliferation, but it also can cause negative effects such as tissue organ fibrosis (33). It's been reported that the mice that have knocked out the 
TGF- $\beta 1$ gene died of systemic inflammation soon after birth because of the loss of inhibition of inflammation (34), This limits the use of therapeutic strategies that antagonize TGF- $\beta 1$ as a treatment target. The expression of CTGF is low and it's mainly expressed in the stroma cell, the effect is also limited to connective tissue, antagonizes CTGF without adverse clinical response may occur after blocking TGF- $\beta 1$ (35). Therefore, the anti-fibrotic effects can be achieved by blocking CTGF and it may be potentially more specific and safer than TGF- $\beta 1$.

Several published studies (36-39) have shown that thalidomide has a certain therapeutic effect on liver, kidney, lung and other organ fibrosis. Previous study has found that thalidomide can increase the overall clinical treatment efficiency, reduce the lesion region in the chest CT and improved the lung function in elderly patients with pulmonary fibrosis (40). Besides, it's been reported that thalidomide can reduce the expression of IL-18 and TNF- $\alpha$ in the alveolar lavage fluid in patients with IPF (41). It can be seen that thalidomide potential provides a good antipulmonary fibrosis effect $(42,43)$. However, the underlying mechanism remains unclear. To further understand the antifibrotic mechanism of thalidomide, this present study used the luciferase reporter gene system to observe the effect of thalidomide on the activity of the CTGF gene promoter. In this experimental study, we have constructed the CTGF promoter-driven luciferase reporter vector pGL3-CTGFP and have transfected it into HELF as a test for the effect of thalidomide on CTGF gene promoter activity. The results showed thalidomide could significantly inhibit the gene promoter of CTGF in HELF.

Several limitations in this present study must be considered. Firstly, due to budget limitation, we only used the luciferase reporter gene system to observe the effect of thalidomide on the activity of the CTGF gene promoter, no other experiments were performed. Secondly, we only detect the effects of thalidomide con gene promoter of CTGF in vitro but not in vivo, further investigations in vivo are highlighted in future studies. Thirdly, we only identified the potential relationship among thalidomide, CTGF and TGF- $\beta 1$, the underlying mechanisms remain unclear, which warrant further investigations.

In conclusion, this present study has found that thalidomide produces a significant inhibitory effect on the activation of CTGF promoter induced by TGF- $\beta 1$, and this effect may be closely associated with the antifibrosis effect of thalidomide. This finding of thalidomide could significantly inhibit the gene promoter of CTGF in
HELF may provide new insights into the treatment of antipulmonary fibrosis. However, the underlying mechanisms for the role of thalidomide on pulmonary fibrosis warrant further investigation in the future.

\section{Acknowledgments}

Funding: None.

\section{Footnote}

Conflicts of Interest: All authors have completed the ICMJE uniform disclosure form (available at http://dx.doi. org/10.21037/apm-19-398). The authors have no conflicts of interest to declare.

Ethical Statement: The authors are accountable for all aspects of the work in ensuring that questions related to the accuracy or integrity of any part of the work are appropriately investigated and resolved. This present study obtained ethics approval from the ethics committee of our hospital (2018-1029-c1) and was conducted in accordance with the Declaration of Helsinki (as revised in 2013).

Open Access Statement: This is an Open Access article distributed in accordance with the Creative Commons Attribution-NonCommercial-NoDerivs 4.0 International License (CC BY-NC-ND 4.0), which permits the noncommercial replication and distribution of the article with the strict proviso that no changes or edits are made and the original work is properly cited (including links to both the formal publication through the relevant DOI and the license). See: https://creativecommons.org/licenses/by-nc-nd/4.0/.

\section{References}

1. Raghu G, Chen SY, Yeh WS, et al. Idiopathic pulmonary fibrosis in US Medicare beneficiaries aged 65 years and older: incidence, prevalence, and survival, 2001-11. Lancet Respir Med 2014;2:566-72.

2. Wuyts WA, Wijsenbeek M, Bondue B, et al. Idiopathic Pulmonary Fibrosis: Best Practice in Monitoring and Managing a Relentless Fibrotic Disease. Respiration 2020;99:73-82.

3. Wallaert B, Duthoit L, Drumez E, et al. Long-term evaluation of home-based pulmonary rehabilitation in patients with fibrotic idiopathic interstitial pneumonias. ERJ Open Res 2019;5:00045-2019. 
4. Kinoshita T, Goto T. Molecular Mechanisms of Pulmonary Fibrogenesis and Its Progression to Lung Cancer: A Review. Int J Mol Sci 2019;20:1461.

5. Pardo A, Selman M. Lung Fibroblasts, Aging, and Idiopathic Pulmonary Fibrosis. Ann Am Thorac Soc 2016;13 Suppl 5:S417-21.

6. Hadjicharalambous MR, Lindsay MA. Idiopathic Pulmonary Fibrosis: Pathogenesis and the Emerging Role of Long Non-Coding RNAs. Int J Mol Sci 2020;21:524.

7. Yang F, Luo L, Zhu ZD, et al. Chlorogenic Acid Inhibits Liver Fibrosis by Blocking the miR-21-Regulated TGFbeta1/Smad7 Signaling Pathway in Vitro and in Vivo. Front Pharmacol 2017;8:929.

8. Kalluri M, Luppi F, Ferrara G. What Patients With Idiopathic Pulmonary Fibrosis and Caregivers Want: Filling the Gaps With Patient Reported Outcomes and Experience Measures. Am J Med 2020;133:281-9.

9. Nemer G, Khalil A. A Cautious Note on Thalidomide Usage in Cancer Treatment: Genetic Profiling of the TBX2 Sub-Family Gene Expression is Required. Drug Res (Stuttg) 2019;69:512-8.

10. van Beurden-Tan CHY, Franken MG, Blommestein HM, et al. Systematic Literature Review and Network Meta-Analysis of Treatment Outcomes in Relapsed and/or Refractory Multiple Myeloma. J Clin Oncol 2017;35:1312-9.

11. Bajwah S, Ross JR, Peacock JL, et al. Interventions to improve symptoms and quality of life of patients with fibrotic interstitial lung disease: a systematic review of the literature. Thorax 2013;68:867-79.

12. Varone F, Inoue Y, Richeldi L. Twenty-five years of Respirology: Advances in idiopathic pulmonary fibrosis. Respirology 2020;25:20-2.

13. Vietri L, Cameli P, Perruzza M, et al. Pirfenidone in idiopathic pulmonary fibrosis: real-life experience in the referral centre of Siena. Ther Adv Respir Dis 2020;14:1753466620906326.

14. Zhang WG, He L, Shi XM, et al. Regulation of transplanted mesenchymal stem cells by the lung progenitor niche in rats with chronic obstructive pulmonary disease. Respir Res 2014;15:33.

15. Laskin DL, Malaviya R, Laskin JD. Role of Macrophages in Acute Lung Injury and Chronic Fibrosis Induced by Pulmonary Toxicants. Toxicol Sci 2019;168:287-301.

16. Ponticos M, Holmes AM, Shi-Wen X, et al. Pivotal role of connective tissue growth factor in lung fibrosis: MAPKdependent transcriptional activation of type I collagen. Arthritis Rheum 2009;60:2142-55.
17. Chang J, Zhou Y, Cong G, et al. Dendrobium candidum protects against diabetic kidney lesions through regulating vascular endothelial growth factor, Glucose Transporter 1 , and connective tissue growth factor expression in rats. J Cell Biochem 2019;120:13924-31.

18. Yang Z, Sun Z, Liu H, et al. Connective tissue growth factor stimulates the proliferation, migration and differentiation of lung fibroblasts during paraquat-induced pulmonary fibrosis. Mol Med Rep 2015;12:1091-7.

19. Moodley Y. In search for a predictive marker of acute exacerbations of idiopathic pulmonary fibrosis. Respirology 2020;25:234-5.

20. Huang M, Yang H, Zhu L, et al. Inhibition of connective tissue growth factor attenuates paraquat-induced lung fibrosis in a human MRC-5 cell line. Environ Toxicol 2016;31:1620-6.

21. Kinashi H, Falke LL, Nguyen TQ, et al. Connective tissue growth factor regulates fibrosis-associated renal lymphangiogenesis. Kidney Int 2017;92:850-63.

22. Xu X, Wan X, Geng J, et al. Rapamycin regulates connective tissue growth factor expression of lung epithelial cells via phosphoinositide 3-kinase. Exp Biol Med (Maywood) 2013;238:1082-94.

23. van Batenburg AA, Kazemier KM, van Oosterhout MFM, et al. From organ to cell: Multi-level telomere length assessment in patients with idiopathic pulmonary fibrosis. PLoS One 2020;15:e0226785.

24. Oruqaj G, Karnati S, Vijayan V, et al. Compromised peroxisomes in idiopathic pulmonary fibrosis, a vicious cycle inducing a higher fibrotic response via TGF-beta signaling. Proc Natl Acad Sci U S A 2015;112:E2048-57.

25. Leask A, Abraham DJ. TGF-beta signaling and the fibrotic response. FASEB J 2004;18:816-27.

26. Li F, Xu X, Geng J, et al. The autocrine CXCR4/CXCL12 axis contributes to lung fibrosis through modulation of lung fibroblast activity. Exp Ther Med 2020;19:1844-54.

27. Meng XM, Nikolic-Paterson DJ, Lan HY. TGFbeta: the master regulator of fibrosis. Nat Rev Nephrol 2016;12:325-38.

28. Loboda A, Sobczak M, Jozkowicz A, et al. TGF-beta1/ Smads and miR-21 in Renal Fibrosis and Inflammation. Mediators Inflamm 2016;2016:8319283.

29. Tachaudomdach C, Kantachuvesiri S, Changsirikulchai S, et al. Connective tissue growth factor gene expression and decline in renal function in lupus nephritis. Exp Ther Med 2012;3:713-8

30. Cheng JC, Chang HM, Leung PCK. TGF-beta1 Inhibits Human Trophoblast Cell Invasion by Upregulating 
Connective Tissue Growth Factor Expression.

Endocrinology 2017;158:3620-8.

31. Cheng JC, Chang HM, Fang L, et al. TGF-beta1 UpRegulates Connective Tissue Growth Factor Expression in Human Granulosa Cells through Smad and ERK1/2 Signaling Pathways. PLoS One 2015;10:e0126532.

32. Toda N, Mukoyama M, Yanagita M, et al. CTGF in kidney fibrosis and glomerulonephritis. Inflamm Regen 2018;38:14.

33. Theron AJ, Anderson R, Rossouw TM, et al. The Role of Transforming Growth Factor Beta-1 in the Progression of HIV/AIDS and Development of Non-AIDS-Defining Fibrotic Disorders. Front Immunol 2017;8:1461.

34. Baba A, Tachi M, Ejima Y, et al. Less contribution of mast cells to the progression of renal fibrosis in Rat kidneys with chronic renal failure. Nephrology (Carlton) 2017;22:159-67.

35. Lee SY, Kim SI, Choi ME. Therapeutic targets for treating fibrotic kidney diseases. Transl Res 2015;165:512-30.

36. Dong X, Li X, Li M, et al. Inhibitory effects of thalidomide on bleomycin-induced pulmonary fibrosis in rats via regulation of thioredoxin reductase and inflammations. Am J Transl Res 2017;9:4390-401.

37. Dong X, Li X, Li M, et al. Antiinflammation and

Cite this article as: $\mathrm{Wu} \mathrm{Y,} \mathrm{Liu} \mathrm{L,} \mathrm{Zhang} \mathrm{J,} \mathrm{Huang} \mathrm{L,} \mathrm{Huang}$ $\mathrm{S}, \mathrm{He} \mathrm{J}$. Thalidomide inhibits the gene promoter of connective tissue growth factor in human embryonic lung fibroblasts. Ann Palliat Med 2020;9(5):2516-2523. doi: 10.21037/apm-19-398
Antioxidant Effects of Thalidomide on Pulmonary Fibrosis in Mice and Human Lung Fibroblasts. Inflammation 2017;40:1836-46.

38. El Ati Z, Lamia R, Cherif J, et al. Thalidomide-induced bronchiolitis obliterans organizing pneumonia in a patient with multiple myeloma. Saudi J Kidney Dis Transpl 2019;30:974-7.

39. Tsai YR, Tweedie D, Navas-Enamorado I, et al. Pomalidomide Reduces Ischemic Brain Injury in Rodents. Cell Transplant 2019;28:439-50.

40. Horton MR, Hallowell RW. Revisiting thalidomide: fighting with caution against idiopathic pulmonary fibrosis. Drugs Today (Barc) 2012;48:661-71.

41. Ye Q, Chen B, Tong Z, et al. Thalidomide reduces IL-18, IL-8 and TNF-alpha release from alveolar macrophages in interstitial lung disease. Eur Respir J 2006;28:824-31.

42. Ohashi K, Nishimura R, Sugimoto S, et al. Effectiveness of pulmonary vasodilators on pulmonary hypertension associated with POEMS syndrome. Respirol Case Rep 2019;7:e00411.

43. Buscarini E, Botella LM, Geisthoff U, et al. Safety of thalidomide and bevacizumab in patients with hereditary hemorrhagic telangiectasia. Orphanet J Rare Dis 2019;14:28. 